\title{
More scientific thinking needed to feed society: The NSTF tackles hunger
}

Food shortages, hunger, starvation and serious problems with long-term food security are far from new issues in Africa, nor in the rest of the developing world. The most recent figures for Africa suggest that $20 \%$ of the population (some 233 million, mostly young, people) face dire hunger on a daily basis. This number also represents more than a quarter of the global figure for people who live with hunger bordering on starvation.

The geographical distribution of the crisis in sub-Saharan Africa is uneven, with those countries whose environmental conditions are least suitable for agriculture, and/or those which have been subject to prolonged periods of warfare or internal social conflict and poor governance, being the most severely at risk. In more recent years, the broad effects of global climate change and the prolonged effect of the current El Niño phenomenon have intensified the problem.

Ethiopia, South Sudan, Zimbabwe, Malawi, Angola and Mozambique are all at risk, while South Africa will, this year, possibly cull some 800000 head of cattle, and import at least 300000 tonnes of maize (and pay with a weakened rand). As a result, this 'old' topic has become increasingly important in current research and development. The South African Department of Science and Technology created, through the National Research Foundation, a Centre of Excellence and Chair in Food Security, shared by the Universities of Pretoria and the Western Cape in 2015. A recent article in The Conversation makes the following points:

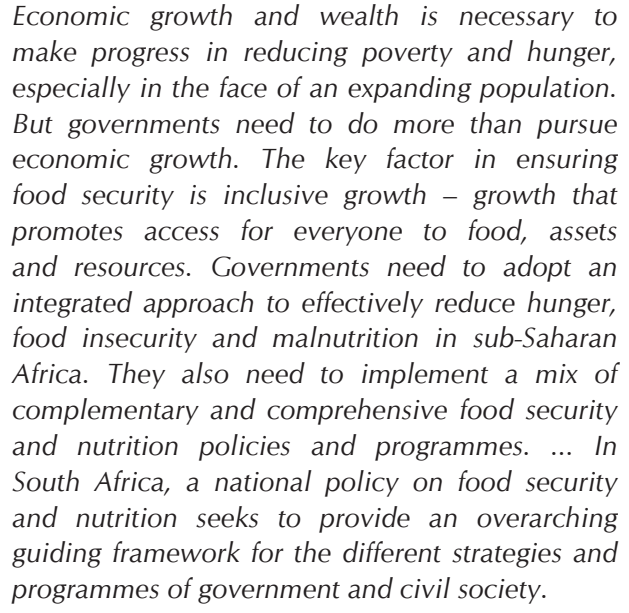

However, underlying such broad social and economic development, and government policies, is the need for substantial and reliable scientific knowledge and the means for its implementation. It is this essential set of conditions needed to address hunger and food security that South Africa's National Science and Technology Forum (NSTF) has addressed through a 'Discussion Forum on Pulses and Food Security', held in June this year (the UN's International Year of Pulses). Partners in this NSTF meeting included the Department of Science and Technology (the sponsors), the Department of Agriculture, Forestry and Fisheries, and AGT Foods /Advanced Seed, Africa.

The importance of the Forum lies not just in its theme and its public and private sector partners, but in the issues raised and recommendations made by those attending the event. These are also placed in the wider context of an ongoing parliamentary debate as to what constitutes an adequate social security payment to feed a South African family in an adequate manner
The preliminary findings of the NSTF meeting make the critical point that, while food is a human necessity, food products are also commodities, which gives rise to 'competing interests' - those of the consumers, for adequate food is a basic human right, and those of the players along the food value chain who feel entitled to compensation for their role in growing agricultural food and moving it into the consumers' market place. This challenge is not, of course, unique to South Africa, but is part of the worldwide problem: the world produces more food than paying consumers really need, resulting in substantial waste, while hunger and starvation remain endemic, primarily in developing regions of the world.

In South Arica, the case is intensified by two conditions: a highly unequal distribution of land ownership and, more importantly when it comes to food production, the general suitability of agricultural land in the country for production. Of this land surface, $12 \%$ has high agricultural potential, $22 \%$ is suitable for production, while $66 \%$ is only marginally suitable for production - in short, of the total agricultural land area, only $34 \%$ is effectively usable. Yet mining activities erode a fair proportion of that $34 \%$. As a result, fewer and fewer people are engaged in food production while, at the same time, the demand for adequate food is increasing as the population grows - which means that the most vulnerable sector of the 'at risk' population in relation to hunger is that of young people.

The preliminary report of the NSTF meeting provides four recommendations:

1. The need for better communication among producers, distributors and consumers in the food supply chain so that expectations are aligned and the food supply chain is less vulnerable to competing interests.

2. The need for collaboration - not only across the food supply chain but between government and the private sector and between governmental departments.

3. The recognition of indigenous knowledge systems around food security.

4. The urgent need for investment in research and development - in other words, in relevant science and technology and the implementation of the outcome of scientific and developmental work

The significance of the first and fourth recommendations is underscored by the debate around what might be considered to be the minimum level of funding that will secure sufficient nutritious food for a low-income family. It is the view of the South African Minister for Social Development that ZAR753 a month is sufficient to feed a low-income family of five people - a figure that was hotly debated and contested in Parliament this June. Best estimates, which take account of the impact of drought and the effects of El Niño on food prices, suggest that the minimum figure for the most basic basket of food for a family of five is, in fact, closer to ZAR1147 a month $-52 \%$ more than the figure cited by the Minister.

It would seem that the food supply chain is subject not only to competitors, but also to inaccurate, and possibly opportunistic, political assessments.

All the more reason for more rigorous science, better insights, and fewer opportunities for guess work at the expense of low-income, hungry families.

HOW TO CITE: Butler-Adam J. More scientific thinking needed to feed society: The NSTF tackles hunger. S Afr J Sci. 2016;112(7/8), Art. \#a0168, 1 page. http:// dx.doi.org/10.17159/sajs.2016/a0168 